\section{Valores y Lenguaje} \\ Autor: Ciro Hernández Valderrama \\ Instituto Universitario de Tecnología Puerto Cabello, IUTPC \\ cirohv@hotmail.com \\ Puerto Cabello, Venezuela
}

\title{
Resumen
}

La pretensión de este ensayo abordó la indagación socio-lingüística e investigación documental educativa, y se redactó en atención a la condición natural que tiene el protagonista social, para transmitir valores desde la acción prosaica y expresión oral en la vida cotidiana, en inmanencia con el sentido figurado. Es a través de expresiones saturadas de mundos imaginarios que el ser social debate y comprende en comunicación fluida, de allí la práctica natural del uso tácito de expresiones coloquiales contentivas de valoraciones. Esta parece la manera sui generis por la que se reconoce el hombre en la sinergia más creativa de idiosincrasia cultural. Sugerimos la educación para abordar este fenómeno y organizar el imaginario de sus actores en los predios pedagógicos, a los fines de comprender e interpretar las diversas creencias, sentimientos, emociones e ideas que, desde el arete circunstancial de la metáfora, emergen para reforzar y posicionar valores.

Palabras clave: valores y lenguaje; expresión metafórica; valores y símbolos. 


\title{
Values and Language
}

\begin{abstract}
The aim of this essay presented the socio-linguistic inquiry and educational documentary research, and it was written in response to the natural condition that has social protagonist, to transmit values from the prosaic action and speaking in everyday life, in immanence with figuratively. It is through saturated expressions of imaginary worlds that social human being debates and understands in fluid communication, hence the natural practice of the tacit use of colloquialisms reserved of evaluations. This seems sui generis way by which the man is recognized in the most creative synergy of cultural identity. We suggest the education to present this phenomenon and organize the imagination of the actors in the educational premises, in order to understand and interpret the various beliefs, feelings, emotions and ideas that from the circumstantial earring of metaphor emerge to strengthen and position values.
\end{abstract}

Keywords: values and language; metaphorical expression; values and symbols. 


\section{Introducción}

Abordamos el tránsito de la orientación verbal imaginaria como el protagonista social para expresar valoraciones, sentimientos, emociones y pasiones a los demás congéneres que constituyen el entorno viviente. Al parecer, las expresiones orales que se ejecutan se construyen como una tela de araña y su vital vínculo es el insondable pensamiento que emerge partiendo de la realidad objetiva, inmanente siempre en la palabra y el orden de la comunicación cotidiana, para deslumbrar en una verdadera y no menos infinita ontología metafórica.

El lenguaje metafórico existe en toda comunicación, esa suele ser la natural manera de referenciar las interpretaciones que constituyen la realidad. De tal manera, las narraciones desde la praxis particular sean analogía, chistes, refranes, anécdotas, parábolas, cuentos o coplas, son producto de la imaginación-contexto, independientemente de que se tenga conciencia o no de su presencia literal en la conversación cotidiana.

Por lo común, en una plática los interlocutores se expresan con figuras imaginadas para sustentar el lenguaje común y referirse a la realidad cotidiana y objetiva que los sumerge. Se trata de superponer figuras mentales al lenguaje literal y contexto real, y a partir de esta transformación, abrir una constelación de interpretaciones y comparaciones. Una metáfora constituye el uso no literal de expresiones referidas a objetos o cosas, con la intención de proponer una comparación tácita y avanzar en la comprensión con el interlocutor.

Rasgo esencial de la expresión metafórica es que el lenguaje utilizado contiene una polisemia amplia, con expresiones que traducen valores morales insertos, dado que los términos utilizados presentan diversos e imprevisibles significados para los que escuchan y ven al interlocutor, de allí podrían emerger nuevas racionalidades de sujeto o sujetos que presencian el relato, atribuyéndole significantes con diversos sentidos, dentro de su esquema de 
vida y conocimiento personal o colectivo, y podría contribuir a reforzar los sentimientos de amor, responsabilidad, respeto, así como encontrar una viabilidad a los de culpa, rencor, rabia; y promover la construcción de la paz personal y colectiva.

Ergo, somos autores directos e interdependientes en los valores y éstos existen para nosotros en la medida que los rescatamos en forma de metáforas, partiendo de la realidad ontológica diaria. De tal manera, los vivimos y construimos cotidianamente en la consciencia e inconsciencia del ser metafórico; lo importante de esto, no es el discurso rimbombante de los valores, sino la dependencia y la relación dialógico recursiva que experimentamos cuando interactuamos en valores, porque es evidente que valor-hombre es un binomio inseparable de relación histórico-lingüística establecida.

En este sentido, su constituyente básico estructural (lenguaje, emociones, contexto) es fuente interactuante en las relaciones persistentes e inagotables que manifiesta su organización en lo social y cultural. El ámbito de la expresión metafórica, parece ser un paradigma de la conciencia del deber ser en la comunicación e información social, acogido por el hombre como idea ejemplar de sus actos comprensivos. Diremos que, en dicho ámbito, está implícito el campo del lenguaje de gestos y posturas personal-colectivas, como factores sine qua non presentes en el correcto proceder del hombre en la convivencia histórica. Es de esta manera, como nos reconocemos y debatimos entre este fenómeno del intelecto, componente de la realidad socioontológica e inmanente en la conducta humana.

No pretendemos en este documento un estudio semántico o análisis de discurso, sino connotar que las experiencias comunicativas que realizamos con los valores, es también obra de expresiones teñidas de lenguaje metafórico en acción, por tanto, es imprescindible como investigadores explayarnos en la configuración de este fenómeno. 


\section{Valores en el Imaginario del Lenguaje Metafórico}

Metafóricamente hablando el individuo dentro de la sociedad y la escuela, es parte integral de un interminable concierto de valores, similares a instrumentos musicales, que opera en una escala de sonidos altos y bajos, a manera de crear la mejor armonía posible para beneficio de los presentes; en un concierto musical cada uno de los participantes vive momentos personales compartidos con el grupo. (Hernández, 2015:6), dado que los mismos constituye un proceso de conocimiento, envuelto en una red dinámica de relaciones personales y colectivas, en constante cambio, construcción y reconstrucción fenoménica.

Efectivamente, la metáfora podría no ser más que el combustible que mueve la conciencia a superar la dialéctica lingüística que se establece entre la realidad objetiva y el lenguaje, desde el momento en que el segundo, para consolidarse, pretende anteponerse al primero. Así lo primordial de la expresión metafórica sería difundir las interpretaciones valorativas y emergentes del pragma social, a fin de reconstruir, a través de los sentimientos expresados, las diversas vivencias de aquello que se narra. De modo que la pretensión general de esta reflexión, consiste en evidenciar el poder lingüístico de la expresión metafórica en el diálogo y en la interpretación del otro para orientar sus experiencias y mundo de vida cotidiano. Según Garciandía (2011):

El lenguaje junto con la corporalidad y las emociones constituye una triada en cuyos dominios particulares suceden fenómenos de la esfera humana... $Y$ en un sentido relacional existe circularidad que hace del vínculo entre estos elementos, un juego coherente y coordinado de retroacciones, cuya finalidad es transmitir la coherencia de todo el individuo consigo mismo y con su interlocutor (pág. 277).

De allí, que la acción pedagógica en el contexto educativo no está exenta del uso deliberado de este recurso lingüístico, para contribuir a reforzar y construir valores morales y entender mejor el comportamiento personal y 
colectivo. Más que una imagen, en el complejo sistema corporal lo que ocurre es un proceso de pensamiento o ideas. Obviamente, la docencia no puede ser pensada como un trabajo individual, personal e influyente. No puede definirse como un dominio del saber letrado, con autoridad legítima e inapelable (Hernández, 2012:4).

En términos de realidad objetiva, podemos preguntarnos ¿podrá una persona en formación académica, transmitir una porción de sus valores a través de expresiones que denotan imaginación metafórica? Seguramente la respuesta es afirmativa, pero lo más viable a comentar, es que se trata de una confusa hilaza ontológica inaprehensible en su totalidad.

Con lo dicho, pretendemos decir que la noción de valor, es una distinción propuesta en el verbo, para explayar la multidimensionalidad del comportamiento del hombre, es así, como en la familia y la escuela, nos reconocemos en valores éticos, morales, sociales, culturales, personales, jurídicos, religiosos y deportivos entre otros. En efecto, las grandes obras literarias como la Santa Biblia, cuyo contenido textual advierte una deslumbrante parábola, su análisis, es infinito metafóricamente hablando, porqué la interpretación literal, abre un contexto y un espacio histórico, para recrear la imaginación y comparación de hechos registrados antes de Cristo y después de Cristo.

La metáfora como fenómeno socio-comunicacional, constituye un mecanismo pragmático del accionar conductual humano, inherente con el comportamiento personal que denota intención o propósito, es decir, tiene per se un carácter intencional, construido desde la interrelación concienciacontexto. El vehículo asidero de la metáfora es el lenguaje hablado, escrito, mímico, virtual o electrónico, acompañado del espacio fundamental de comunicación que es el contorno y entorno socio-cultural. Este vínculo de relación lingüística constituye un aspecto esencial de confluencia en el comportamiento y las acciones espontáneas de la persona. 
No debe perderse de vista, en consecuencia, que la constitución de la metáfora, está íntimamente acompañado de la infraestructura socioeconómica y político-cultural que intercede su contenido semántico. Es así como a través de la idiosincrasia los pueblos proyectan imágenes idealizantes de inaprehensible polisemia a favor de la experiencia cotidiana.

Una metáfora no se concibe sino en relación con los referentes. Es el referente el que se metaforiza, y no su representación lingüística. "Si el lenguaje, al construirse en lo más profundo de la mente, es distancia que se toma con la experiencia referencial, le toca al discurso metafórico, es decir a la poiesis, restituir al referente, ahora redescubierto más allá de la estructura lingüística, su originaria primordialidad". (Molho, 1977:18).

La metáfora se fundamenta en el manejo del concepto, resulta de un juego de analogías y correspondencias es un acto del entendimiento que exprime la correspondencia que se haya entre los objetos. Se ha visto que el concepto metafórico no puede edificarse sino es por regresión al referente a fin de instituir, bajo un significante único, una correlación no ya entre ideas, sino, a través de las ideas, entre las experiencias de la que son transposición mental (Molho, ob.cit:19).

La actividad creadora del espíritu cuando opera con y sobre el lenguaje, esto consiste en concebir correspondencias entre objetos ideales que la mente manipula y ordena y cuyo efecto es construir conjuntos mentales fundados sobre la analogía de los objetos en causa. El relato metafórico conlleva en el lenguaje multitud de sentidos. Pero el crítico opta, de entrada, por la acepción más trivial y menos congruente. Se trata a través del concepto, establecer entre los objetos significados una red abierta de correspondencias. Un hábito mental, revelador, sin duda de instintos o pulsiones profundas que no es momento de descifrar.

La experiencia transmutada en lenguaje y, por el lenguaje en un metalenguaje metafórico, origina conceptos. Las consideraciones anteriores 
no atañen a través del análisis gramatical, más que a la literalidad del texto. El lenguaje por la multiplicidad de relaciones que establece, edifica una pluralidad de lecturas literales, y cada lectura corresponde a un estado en la definición de la estructura. Lo que de ordinario se entiende por sentido literal no es otra cosa que un estado privilegiado de literalidad.

La búsqueda de un rasgo fundamental en el uso deliberado de la metáfora y el lenguaje utilizado, da pluralidad de sentidos orientados a la creatividad del pensamiento racional. No debe olvidarse, sin embargo, que la existencia en el significante de uno o varios significados ocultos se explica por qué el lenguaje es el vehículo obligado de toda clase de impresiones, de fantasías y símbolos que se despliegan en estado crítico, y que, por muy profundamente que estén escondidos bajo la aparente inocencia de la expresión, no dejan por eso de existir, actuando sin descanso en el intercambio oculto que constituye la palabra oral.

\section{3. ¿Por qué la Expresión Metafórica?}

Porque el individuo es esencialmente una entidad hablante, pensante y expresa su naturaleza subjetiva en lenguaje, dentro del sistema de sentidos de la vida cotidiana, de manera tal, que favorece la urdimbre el pensamiento con el lenguaje figurado. Promueve el descubrimiento, la estima, el esfuerzo, el trabajo y el estudio como fuentes de avance personal y colectivo.

Se aprende para la vida, en comunicación verbal figurada, porque aprendemos a extrapolar el mensaje a situaciones nuevas. Esto nos ayuda a deshacernos de la mediocridad y el conformismo. Nuestro sistema conceptual de vida común, en términos del cual interpretamos la realidad y cohabitamos, es fundamentalmente de naturaleza metafórica (Lakoff y Johnson 1998:41) Los recursos audiovisuales y tecnológicos de la actualidad, constituyen una herramienta extraordinaria para proyectar y explicitar imágenes. 
El conversar cotidiano es de origen imaginario, dado la contemplación del hombre ante los fenómenos naturales, asimismo por lo social: nos permite explicitar lo observado, manifestar lo sentido, lo vivido; hablar sobre la realidad y como suceden las cosas, además puede hacer que las cosas ocurran. De este modo el lenguaje se erige como una dimensión generadora de ideas y, por tanto, constructor-coordinador de realidades.

Más allá de describir el mundo y las cosas del mismo, es capaz de crear el mundo, de fundar la realidad, de crear realidades; no siempre es precedido por las cosas que describe, también puede preceder a las cosas que describe al crearlas en sus enunciados. El lenguaje tiene pues, un carácter también ontológico, es generador de ser. (Garciandía: 278).

\subsection{Por qué el lenguaje imaginario en la acción pedagógica}

El origen y el propósito del proceso educativo en cualquiera de sus niveles, se encuentra en el estudiante, de allí que las herramientas de enseñanza deben nacer de sus necesidades, e intereses e iniciativa de aprendizaje. Por ello, la necesidad del relato metafórico desde edades tempranas, por presentar características cognitivas de transición del pensamiento concreto al pensamiento formal, por la inestabilidad y fragilidad emocional de los estudiantes que inician el periodo de adolescencia.

En los programas curriculares de los niveles educativos, se dice que los valores esenciales para la identidad venezolana son entre otros: amor, ternura, libertad, paz, justicia, equidad, solidaridad respeto, convivencia, vida, responsabilidad salud. Sin embargo, en la realidad no se está logrando mucho, porque no los desmenuzamos, no los hacemos actitudes, no los expresamos, nos quedamos en el valor y no vamos a la actividad que es la que debe cumplirse. Es en este punto en el cual, la metáfora llena el vacío y facilita o asiste el trabajo pedagógico. 
Al respecto, el ordenamiento jurídico venezolano la Constitución de la República Bolivariana de Venezuela. (1999), artículo 3 propugna como valores superiores: la vida, libertad, justicia, igualdad, solidaridad, democracia, responsabilidad social y en general la preeminencia de los derechos humanos, la ética y el pluralismo político (p.4) De igual forma los principios y valores rectores de la educación venezolana, el artículo $N^{\circ} 3$ de la Ley orgánica de Educación (2009) considera:

...como valores fundamentales el respeto a la vida, el amor y la fraternidad, la convivencia armónica en el marco de la solidaridad, la corresponsabilidad, la cooperación, la tolerancia y la valoración del bien común, la valoración social y ética del trabajo, el respeto a la diversidad propia de los diferentes grupos humanos... (págs. 3-4).

En atención a lo expuesto, se recomienda de manera transversal la narración metafórica en valores, dirigida por personas responsables y de buena voluntad, en programas de educación preventiva, en forma de encuentros para la reflexión, foros y charlas a orientadores, profesores, psicólogos, padres, representantes, hijos e hijas, alumnado y demás personas que lo requieran. Inclusive, para acompañar técnicas como: el rapport, el anclaje, el reencuadre, representaciones audiovisuales, el dibujo, la música, el canto, danza, teatro, y demás actividades cotidianas durante la clase.

Desde estas ideas, las metáforas que a continuación se mencionan, son un ejemplo, de innumerables narrativas que promueven el trabajo pedagógico, clarifican valores, ejemplifican conceptos, establecen relaciones, distinciones $y$, contextualizan ideas de la idiosincrasia del venezolano. El docente acucioso y moralmente comprometido con la pedagogía, no tendrá obstáculos e impedimentos para crear y difundir nuevas metáforas, veamos: 


\subsection{Metáfora para promover valores superiores}

\subsubsection{La colmena de abejas}

Según los argumentos legales citados, la sociedad venezolana y el sistema educativo, supone su funcionamiento bajo la óptica de la integración y organización social, curricular y pedagógica. Es así como, el trabajo docentealumno, debe ser una labor valorativa sistemática, cuyo contenido teóricoacadémico debe corresponder a los objetivos de enseñanza-aprendizaje, estar conectado con el desempeño administrativo y obrero, para lograr resultados óptimos en el proceso de enseñanza-aprendizaje. Asimismo, en sintonía con las necesidades laborales y de ocupación del país, Sin embargo, en la práctica parece que no se está logrando el trabajo mancomunado, en un escenario con características complejas.

El sistema de relación de los valores y su funcionamiento social en el sistema educativo, puede compararse con lo que sucede en la vida de una colmena; en este espacio de reunión, los actores educativos son como abejas productoras activos de valores, integradas a los preciados panales per se contentivos de miel como valor vital, aferramos a éstos en un consenso natural esencial.

Como humanos empáticamente reunidos en un gran (panal) universo planetario, generamos: vivencias cercanas, valoraciones en los entornos educativos y socio-culturales de relación, implicaciones a la materialidad, transformación en medio de vida compartida, mediante el consenso y la participación activa. Además, estamos en constante movimiento, por un objetivo biológico y recursivo, que es, el permanecer unidos y construir juntos el propio bienestar, cooperación, tolerancia, solidaridad, igualdad, responsabilidad y ética, prolongando así la supervivencia al grupo que nos produce.

En una colmena de abejas, se distribuye el trabajo diario entre todos los integrantes que la constituyen. Cada miembro participa activamente en el 
cumplimiento de sus funciones y responsabilidades específicas. Todos los individuos permanecen unidos por la construcción de su propia casa u hogar. Aun cuando cada individuo, visto por separado, parece contribuir muy poco al mantenimiento y supervivencia de la colmena, no es así, cuando, se concibe sus integrantes, como un todo poiético integrado, con capacidad para autoproducirse.

En un sistema educativo, aún, cuando en lo particular haya diferencias fenotípicas y diversidad de ideas y pensamiento, la tendencia es a permanecer sintonía con la organización y, al mismo tiempo propiciar la renovación para mantener el funcionamiento de cada miembro de los miembros del salón de clases.

En algún sentido kantiano, el significante biológico de este ejercicio de imaginación, guarda relación con la noción de imperativo categórico a priori, al tratarse de una cualidad innata o predisposición natural, anterior a cualquier aprendizaje ulterior, presente en cada organismo vivo, que lo mantiene en permanente emergencia $y$, en constante colaboración recíproca, para cohabitar y construir juntos su propia colmena o sociedad.

Conforme a esta visión, debería transitar entre los venezolanos, la condición bio-psicosocial que los define y los proyecta en la historia, es decir, en sincronía sistémica entre hechos valorativos en relación recíproca con el contenido cultural, dado que ello explicita el accionar social y devela en la temporalidad, el entendimiento armonioso de los valores entre sus miembros.

\subsection{Metáfora pedagógica para promover el trabajo compartido}

\subsubsection{El Río Orinoco}

El proceso pedagógico de enseñanza-aprendizaje, debe compararse al gran río Orinoco, principal arteria de agua dulce que cruza el corazón del territorio venezolano en cuyo interior subyace el trabajo compartido. 
Los alumnos y profesores constituyen el sistema de agua que da vida a la organización denominada Río Orinoco, no pueden vivir separados, ambos se necesitan para proporcionarle nombre y renombre al majestuoso caudal de vitalidad rebosante.

Deben estar unidos como el hidrógeno y el oxígeno para que emerja el agua, si estuvieran separados, serían otra cosa muy distinta al agua, en una molécula, el alumno es el hidrógeno y el profesor es el oxígeno, en proporción, por lo general hay más alumnos que profesores en un aula de clase; al mencionarlos parecen diminutos, pero constituyen per se, el río que sustenta la naturaleza biológica del país.

Dentro de esta imaginación, los peces y demás organismos vivos que nadan en el mismo río, complementan los demás actores administrativos y obreros de la organización, cada uno participando y cumpliendo tareas de aporte de oxígeno, nutrientes, purificación y de mantenimiento del subsistema correspondiente.

Visto el fenómeno pedagógico desde este contexto, tanto profesores como alumnos, proporcionan vida y bienestar a la sociedad, son la fuente natural de la cual se nutre el mundo civilizado, para desarrollarse y producirse, la interrelación compartida entre ellos, permite la autoformación y capacitación que requiere el progreso del país.

Pero el río como escenario educativo constituye un micro sistema, que mantiene relación con otros sistemas circundantes, a quienes provee de valores sociales y conocimiento, de ahí, que reclama cuidado y protección de la misma sociedad. Por lo tanto, esta metáfora advierte errores de tipo teóricoorganizacional y epistemológico que pudiesen cometerse en el proceso educativo venezolano a principios del siglo XXI.

Es necesaria la solidaridad y valoración de éste bien común, para evitar que pierda agua y, se seque, y ponga en riesgo la vida y el bienestar de todos los elementos que lo contienen. No puede pensarse el Homo Sapiens como 
un río de seres, desconectados y sin vida propia. El hecho educativo a la luz del trabajo compartido, debe dar un giro, de manera tal, que al volver en el encuentro, la relación alumno-profesor sea de respeto mutuo en la convivencia de lo que se interpreta como humano.

Desde esta episteme, se justifica la imaginación y el valor simbólico del Río Orinoco, toda vez que dilucida la prospectiva de un escenario ávido de nuevas posturas pedagógicas emergentes en la educación venezolana. Contribuirá, además, a que los actores del escenario educativo, eliminen viejos modelos frustrantes que generan miedo, trabas y bloqueo al estudiante dificultando el aprendizaje.

Cuando el docente activa su repertorio metafórico: se convierte en un agente dinamizador del entorno sociocultural del alumno y su familia. Amplía sus conocimientos pedagógicos y el de las características particulares del alumnado, favoreciendo la interiorización de los valores básicos para la vida y la convivencia, como también los valores sociales, culturales, religiosos, patrios, entre otros, dado que:

Las imágenes que evocan las metáforas invitan a la mente a pensar distinto, a posicionar otros mensajes y a llegar a conclusiones innovadoras, además, abre la posibilidad de interacción dialógica a los jóvenes estudiantes, que llegan a las instituciones con escasa experiencia discursiva, esta herramienta le brindará la oportunidad, de trabajar en grupo y mantener relaciones interpersonales abiertas y positivas. Dado que, La sabiduría del género humano está contenida en parábolas, anécdotas, máximas, fabulas e imágenes.

\section{Metaforizar con el Estudiante}

El sustento que debe mantener la unión padres-hijos y, en al ámbito escolar profesor-estudiante, es el valor de la integración humana de buena voluntad, mediante el lenguaje cotidiano; en ambos actores del fenómeno 
educativo, debe propiciarse la combinación de pareceres y haceres con la interrelación dialógica, siendo que, es a través, del lenguaje que expresamos nuestros valores.

El sistema de valores con el alumno, es comparable con la construcción de una pared, en la que tanto alumno como profesor representa los ladrillos y, el pegamento que une los ladrillos, constituye los valores que relacionan a ambos. La fortaleza de esta pared es mantenida por el lenguaje, elemento fundamental del cual estará hecho el pegamento que proporcionará la calidad del pegamento. Es por ello que, el acto pedagógico docente-alumno, no puede verse asilado en sus experiencias, los valores mismos (pegamento esencial los mantiene unidos) configuran el fenómeno de la socialización educativa, en relación viva y bidireccional.

El cómo lograr un acercamiento humano, está relacionado con el uso de la narración metafórica integrado al contexto familiar, social y educativo, porque de lo que se trata, es de interactuar con una herramienta eficaz, como lo es la imaginación, para reforzar contenidos básicos para la vida y la convivencia, dentro, como fuera de la institución educativa. El contenido de manera general, constituye el bagaje cognitivo, aprendido mediante el acervo socio-cultural y patrones de conducta familiares.

La valoración en el plano educativo, es una práctica cotidiana mediante la cual, un contenido adquiere: significado, necesidad y deseo, es decir, aviva y promueve la disposición hacia la adquisición del mismo, por su alta conveniencia para satisfacer necesidades fundamentales y agregar sentido al proyecto de vida personal. Moreno (2007:35). Las valoraciones actúan como pre-valores que se establecen en el pensamiento y se activan motivados por el entorno, y emergen cuando encuentran el asidero en el medio ambiente compartido.

Estamos hablando de la dimensión subjetiva de las emociones, pasiones y sentimientos ocultos como energía potencial en las interioridades 
de la persona, que se hacen cinéticas en el comportamiento visible, público, notorio y comunicacional. En un ejercicio de imaginación la dimensión subjetiva, semeja ventanales que soplan valoraciones, predispuestos a la apertura de un mutualismo y conversión de gustos y placeres compartidos, en virtud del deseo por la lectura, escritura, planificación, participación activa, diálogo, trabajo compartido, asistencia a clases y eventos científicos.

En las proposiciones iniciadas por el docente, con implícitos ontológicos del ser del vivir-compartir, que refieren encuentros con actos humanos en valores ético-morales, cortesía y buenos modales, no debería faltar en cada una, la narración deliberada de metáforas o metonimias orientadoras, que complementen o acompañen con su verbo imaginario las mencionadas valoraciones. Veamos algunas muestras.

Cuando el docente venezolano, en el encuentro pedagógico con el alumno:

- Promueve la simpatía mediante el saludo amistoso, lo incorpora personalmente a la institución y a la vida estudiantil.

- Atiende pacientemente los interrogantes, enfatiza la autoestima.

- Dialoga amistosamente, lo está convirtiendo en su amigo personal

- Lo acoge como un miembro de su familia, construye respeto y generosidad.

- Caminan juntos, entonces le muestra seguridad en el sendero de la vida.

- Oran acompañados, lo hace su hermano en la fe con Dios..

- Comparten alimentos, construye empatía verdadera

- Leen y escriben juntos, entonces forja hábito de estudio.

- Ofrece invitación a su hogar, está construyendo confianza, seguridad y sensibilidad personal-social. 
Es precisamente, durante los momentos en que ocurren estos encuentros, que el docente concienzudo y habilidoso, busca en su repertorio cognitivo, la metáfora pedagógica más idónea, para narrarla efusivamente a sus estudiantes y connotar valores específicos según las circunstancias. Se trata de momentos sublimes, cargados de contenidos valorativos, por ser del acto pedagógico, que durante un espacio-tiempo concreto, de reflexión moral y vivencias in situ, se pueden expresar libremente.

Consustanciado con las proposiciones expuestas, se infiere que tenemos valoraciones dispuestas a dialogar, es decir un querer mental, del cual nos sentimos agradados y por el cual estamos ansiosos a disfrutarlo; y que, de alguna forma verbal, procuramos argumentarlo y comunicarlo mientras compartimos, se trata pues, de evocar durante el encuentro pedagógico, los vínculos analógicos familia-sociedad-escuela. Pero con el ingrediente de recurrir amorosamente al lenguaje figurado e imaginario, para reforzar nuestras matizadas proposiciones, durante el acto verdaderamente humano y empático con los alumnos.

Ciertamente, la mayor virtud de un profesor es el ser amoroso con sus alumnos al respecto, un aforismo elocuente de la ontología pedagógica, nada es más notable que ver a un profesor, entregado a educar mientras considera que nadie lo observa. En concordancia con esta sentencia moral, el respeto a la dignidad del alumno es un manifiesto pedagógico, subyacente en la formación familiar (Hernández: 90), es desde la enseñanza institucional benevolente, que podemos convertir nuestra labor en un verdadero gozo espiritual, a través del pensamiento, el lenguaje y la comunicación.

El relato metafórico en la interacción diaria escolar, actúa como herramienta cognitiva del proceso enseñanza-aprendizaje $y$, el sentido figurado permite promover la responsabilidad, el respeto, la solidaridad, que antes teníamos enturbiado, oscuro o velado. Asimismo, actúa como elemento 
recursivo, entre docente-alumno-contenido, dado que orienta la construcción y reconstrucción de nuevos significados y atribuye sentido a lo que se aprende.

De este modo, la narrativa metafórica del venezolano de cualquier región del país, es relativamente parecida, es decir, puede extrapolarse a situaciones sociales. La imaginación depende necesariamente de la perspectiva de cada temperamento, contiene en si misma todo el acervo sociocultural y simboliza la actitud del narrador y especialmente las valoraciones personales que subyacen a su sistema de interpretación de la realidad.

Es condición de los valores del hombre su naturaleza con el arraigo verbal, es allí, donde asisten al temperamento del hombre en sociedad, constituyen vigencia histórica y dinamizan el contexto humano de interacción e interrelación. Por ello, no deslumbran cuando están en desuso oral o, el contexto no invita a compartirlos. El lenguaje imaginario es el faro que ilumina el funcionamiento social de los valores: sin el primero, el segundo sería, como los ojos del pez que vive en la oscuridad del cenote, si no disponen de luz, pierden brillo y se tornan innecesarios. Estamos conscientes de esta dimensión de los valores, la abordamos y fundamentamos, pero no por eso está concluida, continúa siendo uno de los más elementales fenómenos de nuestra época a comienzos del tercer milenio.

\section{La Metáfora en la Enseñanza Formal-Moral}

No ha sido suficiente el contenido formal y textual-literal para educar en valores, es necesario transfigurar el mensaje acompañado con ejemplos prácticos para otorgarle imagen concreta al mismo, con ello, el sentido pedagógico de la metáfora aborda el ámbito de la conducta moral, llegando a interesar la percepción de realidad, actitud y posturas de indiferencia. Por otra parte, permite: descubrir y estimular la potencialidad de imaginación de los docentes, llegar a lo más profundo del corazón de los estudiantes y, vislumbrar en estos la aceptación de errores, manifiestos en la percepción del contexto 
mismo. Veamos la metáfora de Gibran (1970), a partir de la cual puede hacerse infinidad de elucubraciones y transformaciones en la enseñanza moral:

Dijo el ojo un día: "Veo más allá de estos valles una montaña velada por la niebla. ¡Cuán bella esj”. Escuchaba el oído, y después de prestar mayor atención, dijo: "Pero ¿Dónde está la montaña? Yo no la oigo". Luego habló la mano, y dijo: En vano trato de sentirla o de tocarla; no encuentro montaña alguna". Y dijo la nariz: "no hay ninguna montaña. No puedo olerla. Entonces el ojo volteó al otro lado y todos comenzaron a discutir acerca de la extraña ilusión del ojo, y dijeron: "Algo grave le habrá sucedido al ojo" (pág. 160).

Desde esta óptica, la narración constructiva, contentiva de figuras sensibles, estimulan el consenso, el acuerdo y la organización en el estudio, ofrecen fuerza expresiva superior al lenguaje ordinario, posibilitando intuir mejor la realidad de nuestras vidas. Con la palabra por delante, el actor educativo ofrece muestras de sus intenciones valorativas, máxime cuando la narrativa es de orden imaginario más que literal-textual. Relatos como el citado, anticipan el realismo crítico, son el comienzo de un proceso de reflexión, discusión y participación, nos sacan del engaño respecto a nosotros mismos, forjando valores, dado que, despierta la perspicacia interpretativa, la dialéctica en el encuentro y, advierte de las múltiples distorsiones del convencionalismo y orden social.

No hay mejor forma de explanar algo, que usar el ejemplo unido a la comparación, en consecuencia durante el espacio-tiempo de la clase, es el momento de ilusionarnos por lo que vamos a vivir, y para que se fijen las nuevas ideas, se pueden relatar ejemplos del dominio empírico.

\section{Apostilla de Cierre}

Las reflexiones hechas en este documento, constituye un espacio epistemológico abierto, para el debate y la reflexión colectiva de las 
experiencias pedagógicas de profesores y profesoras quienes intervienen desde todos los niveles y modalidades del sistema educativo de la República Bolivariana de Venezuela. La educación ante los retos planteados por la aparición de nuevos valores, sabrá crear plena conciencia común y un cemento de solidaridad moral que a todos identifique en propósitos que puedan trascender los límites del interés de cada quien, Hernández (2015).

La formulación y propuestas de constructos acerca de los valores ha desvanecido en un debate titubeante, reverente de posiciones terminales $y$, en consecuencia se ha soslayado la construcción de una teoría del lenguaje metafórico y cotidiano, que lidie y sostenga la exigencia del fenómeno humano, cuyo presupuestos epistemológicos que interroguen, el cómo se conciben los valores en la interrelación conciencia-racionalidad y cómo trascienden la realidad ontológica del mundo social, en inmanencia con expresiones metafóricas.

\section{Referencias}

Constitución de la República Bolivariana de Venezuela (1999). Gaceta Oficial

Extraordinaria $\mathrm{N}^{\circ} 36.860$ de fecha 30 de diciembre. Caracas, Venezuela: Asamblea Nacional Constituyente.

Garciandía, J. (2011). Pensar sistémico. Una introducción al pensamiento sistémico. Bogotá: Pontificia Universidad Javeriana.

Gibran, J. (1970). El loco. Sus parábolas y poemas. Editorial Orión: México. Hernández, C. (2012). Trabajo docente y respeto a la dignidad en el contexto de la educación media venezolana. Tesis Doctoral. Cabudare, Venezuela: Universidad Fermín Toro.

Hernández, C. (2015). El escenario educativo en un concierto de valores. Scientiarum, Revista Científica del Decanato de Investigación y Postgrado de la Universidad Fermín Toro, № 1, 64-73. Depósito legal: PP200802LA2795, ISSN: 18568688. 
Lakoff, G. y Johnson, M. (1998). Las metáforas de la vida cotidiana. Madrid: Cátedra.

Ley Orgánica de Educación (2009). Gaceta Oficial № 5.929 Extraordinario del 15 de agosto. República Bolivariana de Venezuela: La Asamblea Nacional.

Molho, M. (1977). Semántica y poética. España: editorial Crítica. 


\section{Ciro Hernández Valderrama \\ e-mail: cirohv@hotmail.com}

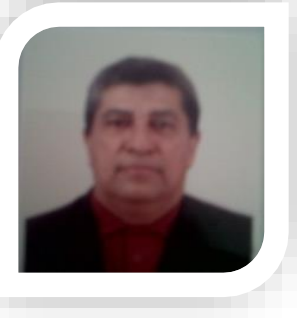

Venezolano nacido en el Estado Trujillo. Licenciado en educación, mención: Orientación egresado de la Universidad de Carabobo. Maestría en Educación Básica (Universidad Nacional Experimental Rómulo Gallegos). Doctor en Ciencias de la Educación (Universidad Fermín Toro). Postdoctor en Estudios

Libres (UFT). Cuya agenda constituye un proceso sistematizado de investigación, producción, análisis y comunicación de conocimientos. Así mismo, la epistemología como reflexión filosófica en torno al estado del arte científico, que pretende dilucidar modos de pensar y conocer los estilos de pensamiento y prácticas en campos disciplinares específicos. Profesor Asociado, coordinador del área Formación Humanista, adscrito a la División de Docencia en Instituto Universitario de Tecnología Puerto Cabello. Venezuela. Coordinador de programas pedagógicos dirigidos a orientación con valores y de convivencia socio-comunitaria. Ponente en congresos académicos. Participante con artículos en revistas científicas. Dictaminador en revistas científicas: ARJE, CIENCIAS DE LA EDUCACIÓN, EDUCARE UPEL IPB, EDUCARE UNA, INVESTIGACIONES INTERACTIVAS COBAIND, SCIENTIARUM Jurado en trabajos de ascenso: UNIPAP, IUTPC. Tutor de tesis UC. Investigador socio-educativo, en la dimensión ético-moral del hombre. Certificado en Programa de Estímulo a la Innovación e Investigación. PEll convocatoria 2015-2016, Investigador A-1, adscrito al Observatorio Nacional de Ciencia Tecnología e Innovación (ONCTI).

El contenido de este manuscrito se difunde bajo una Licencia de Creative Commons ReconocimientoNoComercial-Compartirlgual 4.0 Internacional 